\title{
Erratum
}

\section{Erratum to: Agriculture, Domestic Production, and Site Function: Microfossil Analyses and Late Prehistoric Landscapes of the Society Islands}

Jennifer G. Kahn ${ }^{*, 2}$, Mark Horrocks ${ }^{3,4}$, and Michel K. Nieuwoudt ${ }^{5}$

${ }^{2}$ Department of Anthropology, The College of William and Mary, Williamsburg, Virginia, USA

${ }^{3}$ Microfossil Research Ltd, Auckland, New Zealand

${ }^{4}$ School of Environment, University of Auckland, Auckland, New Zealand

${ }^{5}$ School of Chemical Sciences, University of Auckland, Auckland, New Zealand

*Corresponding author; e-mail: jgkahn01@wm.edu

Erratum to: Journal of Economic Botany

DOI 10.1007/s12231-014-9274-7

The first part of Figure 5 (a-q) was inadvertently

omitted. It is reproduced here. 

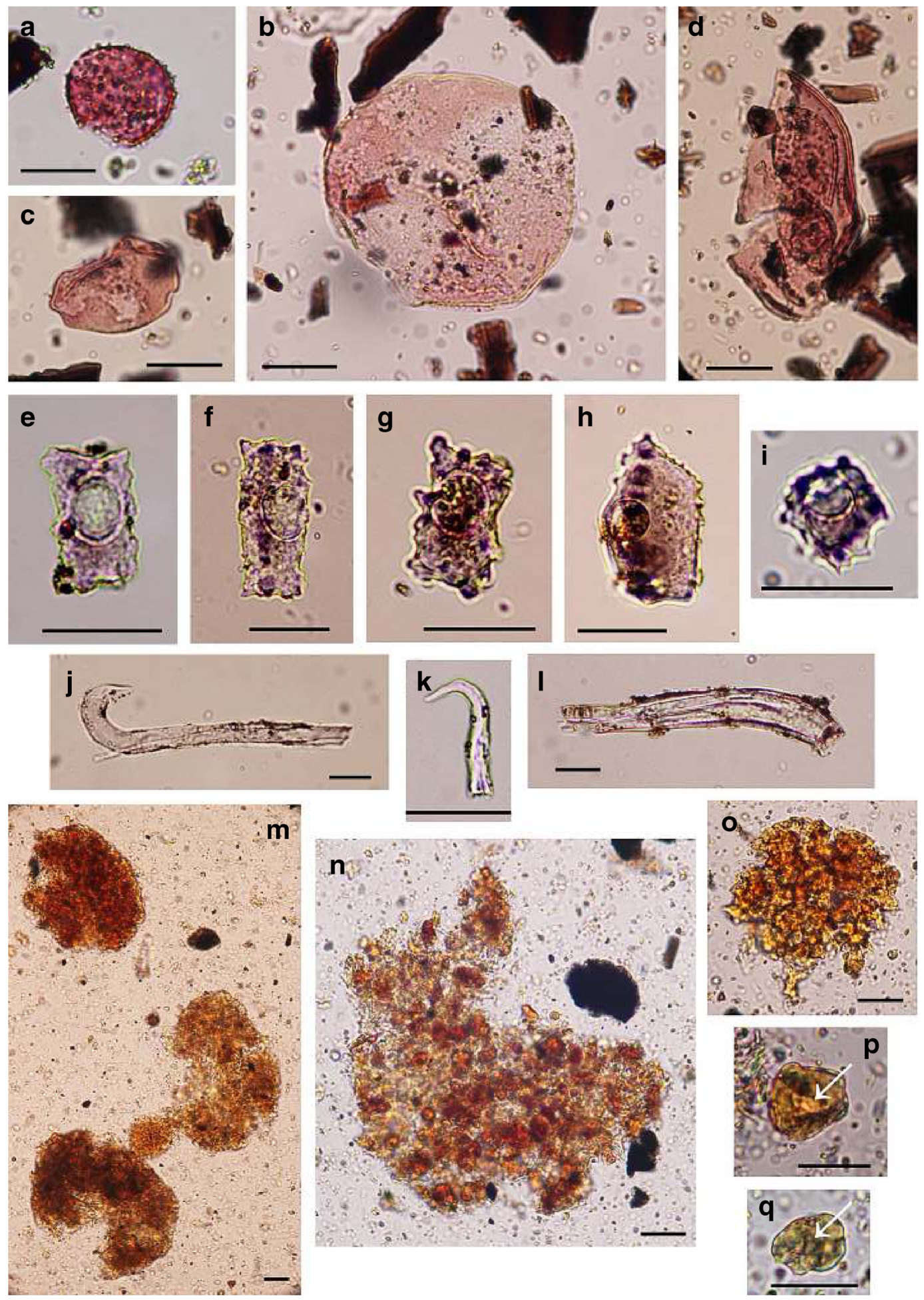